Organizational Communication imperatives Lessons of the Space Program. Phillip K. Tompkins. Los Angeles, Roxbury Publishing company, 1993

\title{
Valérie Carayol
}

\section{(2) OpenEdition}

Journals

Édition électronique

URL : http://journals.openedition.org/communicationorganisation/1644

DOI : 10.4000/communicationorganisation. 1644

ISSN : $1775-3546$

Éditeur

Presses universitaires de Bordeaux

Édition imprimée

Date de publication : 1 mai 1993

ISSN : 1168-5549

Référence électronique

Valérie Carayol, « Organizational Communication imperatives Lessons of the Space Program. Phillip K.

Tompkins. Los Angeles, Roxbury Publishing company, 1993 », Communication et organisation [En ligne], 3 | 1993, mis en ligne le 26 mars 2012, consulté le 19 avril 2019. URL : http://journals.openedition.org/ communicationorganisation/1644; DOI : 10.4000/communicationorganisation.1644

Ce document a été généré automatiquement le 19 avril 2019

(c) Presses universitaires de Bordeaux 


\title{
Organizational Communication imperatives Lessons of the Space Program. Phillip K. Tompkins. Los Angeles, Roxbury Publishing company, 1993
}

\author{
Valérie Carayol
}

1 Phillip Tompkins propose une réflexion sur la communication des organisations à partir d'une étude de cas sur la NASA qui rassemble des observations recueillies sur plus de 25 ans, soit des années 60 jusqu'à la catastrophe de Challenger. L'auteur a, en effet, été consultant pour cette organisation sur une très longue période.

2 Il décrit les valeurs et les pratiques culturelles de la NASA et propose une analyse intéressante de son histoire, notamment en avançant des explications au déclin de l'institution entre 1960 et 1980.

3 Cet enseignant à l'Université du Colorado à BOULDER ne cache pas son intérêt pour une approche psychanalytique de la communication organisationnelle. Il développe dans son ouvrage plusieurs concepts intéressants notamment ceux $d$ »'amnésie institutionnelle » et de «deuil organisationnel». Le premier renvoie au processus lent par lequel des pratiques efficientes ou ayant prouvé leur efficacité ne sont plus encouragées ou mises en œuvre, le second à la situation particulière entraînée par une rupture brutale (tel l'accident de Challenger) dans la vie organisationnelle.

Le livre prend la forme d'un récit écrit à la première personne et évite la forme traditionnelle de l'exposé ou du traité, ce qui lui confère une bonne lisibilité.

On pourra regretter certaines conclusions en forme de plaidoyer pour un programme spatial américain d'envergure qui montrent la difficulté du rôle d'observateur extérieur pendant un partenariat aussi long avec une entreprise. Cette restriction mise à part, il faut souligner l'intérêt d'une étude diachronique de la communication d'une organisation 
telle qu'elle est développée dans l'ouvrage. L'approche est originale et mérite qu'on s'y intéresse. 